\title{
Investigating the Effect of Addition of Olive Husk Ash on Asphalt Binder Properties
}

\author{
Taisir S. Khedaywi ${ }^{1}$, Madhar A. Haddad ${ }^{2 *}$, Arabi N.S. Al Qadi ${ }^{3}$, Owies A. Al-Rababa'ah ${ }^{1}$ \\ ${ }^{1}$ Department of Civil Engineering, Jordan University of Science and Technology, P. O. Box 3030, Irbid 22110, Jordan \\ ${ }^{2}$ Department of Architectural Engineering, United Arab Emirates University, P. O. Box 15551, Al Ain, UAE \\ ${ }^{3}$ College of Engineering, Ajloun National University, P. O. Box 43, Ajloun, 26810, Jordan
}

Corresponding Author Email: madhar@uaeu.ac.ae

https://doi.org/10.18280/acsm.450307

Received: 15 March 2021

Accepted: 26 May 2021

\section{Keywords:}

olive husk ash, asphalt binder, penetration, ductility, flash and fire point, ring and ball test

\begin{abstract}
Flexible pavement is the preferred pavement type in construction of roads and highways. A huge amount of non-renewable materials and industrial products like Olive Husk Ash (OHA), aggregates, bitumen, cement, lime, and other additives are used during the construction and maintenance of the pavement system. Needless to say, the extraction and production of these materials are unmaintainable. Moreover, the wastage of materials, the worsening environmental conditions, the insufficient resources, and the increasing cost of material urged the researchers to look for alternative materials that can be used in flexible pavement. Jordan as many other Mediterranean countries produces a substantial amount of olive oil every year, which in turn produces an enormous amount of olive waste that could lead to environmental problems. Up to now, there is no efficient or certain way in which olive oil waste could be handled or used except that it is sometimes used for heating purposes. The current research aims to evaluate the effects of Olive Husk Ash (OHA) on asphalt binder properties such as penetration ductility, softening point, fire and flashpoint, and specific gravity. In the current research, OHA is used as anditive $(0 \%, 5 \%, 10 \%, 15 \%$, and 20\%) of asphalt-cement. Tests on OHAasphalt binder properties are conducted and results are reported. Results of experimentation and analyses indicate that increasing OHA content in the asphalt-cement binder has resulted in a reduction of both penetration and ductility and an increase in specific gravity, softening point, and fire and flashpoint.
\end{abstract}

\section{INTRODUCTION}

A flexible pavement is a pavement layer comprising of a mixture of aggregates and bitumen, heated and mixed properly and then laid and compacted on a bed of granular layer. A huge amount of non-renewable materials and industrial products like Olive Husk Ash (OHA), aggregates, bitumen, cement, lime, and other additives are consumed during the construction and maintenance of a pavement system. The extraction and production of these new materials is an unmaintainable practice. Wastage of materials, environmental worsening, reduction of resources, and the rise in material cost forced researchers to look for alternative materials that can be used in flexible pavement.

Due to the current high traffic density and loads worldwide, it has become necessary to develop a new asphalt pavement that can withstand these conditions with enough durability and minimum cost of maintenance. Since the 1950s, several procedures and materials such as rubber and ash have been used to improve the behavior of the asphalt mixtures.

Ordinary bituminous mixtures are composed of bitumen, aggregate, and air voids. The behavior of asphalt mixtures depends on the physical and chemical properties of aggregate and asphalt. Several materials have been added to the aggregate binder mix to enhance the behavior of the asphalt mixtures, such as; rubber, oil shale ash, and black carbon. However, a scant of research are found regarding the olive husk ash when added to asphalt mixtures. The following literature summarizes the work that has been achieved to study the effects of several material additives on the behavior of asphalt mixtures.

Al-Massaid et al. [1] investigated the properties of asphalt oil shale ash bituminous mixtures under normal and freezethaw situations. The authors found that the replacement of ash up to ten percent by volume of asphalt binder has improved the behavior of mixtures under both situations. This replacement has resulted in increasing stability, tensile strength, modulus of stiffness, resistance to freeze and thaw damage of the paving mixture compared with mixtures when the ash is not used. Similar studies by Al-Massaid et al. [2] and Al-Mashgbeh [3] indicate that additives, such as rubber, olive husk ash, and ash will increase asphalt mixtures resistance to permanent deformation and fatigue cracking with a cheaper cost than the ordinary asphalt concrete mixtures.

Dartnell [4] performed an experimental study on the use of mineral fillers in asphalt paving mixtures. These mineral fillers are limestone dust, calcined shale, and asbestos. Standard Marshall mix design was used and special reveling and bending tests were conducted. The author concluded that the order of preference of mineral fillers is calcined shale (best), limestone dust, and asbestos.

Al Qadi [5] studied the effect of oil shale ash on fatigue characterization and creep properties of asphalt concrete mixtures. To conduct his study, the author used the Universal Testing Machine (UTM), using Marshall specimens with five levels of oil shale ash $(0,5,10,15$, and $20 \%)$ by volume of 
binder. The author found that oil shale ash content had a slight effect on the accumulated strain, the stiffness modulus, and the resilient modulus.

Khedaywi and Abu-Orabi [6] investigated the effects of oil shale ash, rubber ash, husk ash, and polyethylene on the properties of asphalt-cement. The authors found that the penetration, ductility, and softening point of the mixture were all directly proportional to the amount of the added materials. The authors also found that the specific gravity of the binder was directly proportional to the added amount of ash and inversely proportional to the added amount of polyethylene.

Hui et al. [7] investigated the properties of rubber modified asphalt binder at low temperatures. The authors concluded that some types of rubber, especially the crumb rubber, have increased the fracture toughness of the binder.

Fayer et al. [8] investigated the effect of adding rubber to asphalt. The authors found that using rubber modified asphalt mixtures has resulted in lower crack density and severity which reduce rutting.

Hanson et al. [9] investigated the effect of adding crumb rubber to asphalt mixtures, such as permanent deformation, tensile strength, modulus of resilience, and void in the mix. The authors found that a modified mixture has slightly greater tensile strength than the control mix, but a greater permanent deformation than the control mix.

Alsheyab and Khedaywi [10] investigated the effect of electric arc furnace dust to solve the problem of waste by mixing it with asphalt-cement for the construction of highways The cement mixture was added to the asphalt in different percentages following the volume of the mixture. Ductility, specific gravity, penetration, softening point, flashpoint, fire point, and rotational viscosity were investigated. The authors have reported that both penetration and ductility have decreased with the increase in electric arc furnace dust concentration of the mixture. However, specific gravity, softening point, flash point, fire point, and rotational viscosity have increased with the increase in electric arc furnace dust concentration in the mixture. The authors concluded that the electric arc furnace dust can be used for road construction.

Gautam et al. [11] investigated the effect of using recycled materials in several layers of pavements. The authors indicated that the use of secondary material not only provided an effective waste disposal approach but also reduced both the request on regular material and the total cost of construction. However, their fields of application were limited. The authors suggested several solutions to encourage the use of recycled material in the pavement.

Arafat et al. [12] studied the sustainable lignin that could promote asphalt binder oxidative aging and mix properties. Several kinds of lignin were used as a substitution to six percent of the asphalt mixture to study their effect on the aged and un-aged asphalt mixture. These kinds of lignin are: the kraft lignin, lignin experimentally obtained from black liquor, and lignin experimentally obtained from rice hulls using a special kind of solvent. A control asphalt mixture was also prepared. The high-temperature performance grade was better with the lignin additives. The asphalt mixture with the lignin additives has a greater tolerance of strain compared with the control mixture in the sweep test of strain. The long term index of aging is better when adding either of the lignin obtained from the back liquor or rice hulls to the asphalt mixture. The substitution of the asphalt mixture by six percent of the black liquor lignin is reasonable for hot mixtures and could be to applicable less-hot mixtures.

A review of literature has revealed that little has been accomplished to investigate the effect of OHA when added to asphalt mixtures. Therefore, the current research aims to evaluate the effects of OHA on asphalt binder properties, such as penetration, ductility, softening point, fire and flashpoint, and specific gravity. This research is expected to help resolve the problem of disposal of the olive husk ash. Olive Husk became an environmental problem as waste materials especially in the Middle East where huge quantities are found.

\section{MATERIALS, METHODS AND MEASUREMENTS}

\subsection{Materials}

Asphalt cement (binder) is the liquid bituminous material used as the bonding material in the asphalt mix. Asphalt cement is extremely good as waterproofing material unchanged by almost acids, alkalies, and salts. It is called a thermoplastic material because it unstiffens as it heated and toughens as it cooled. This single subset of characteristics and properties is a basic reason why asphalt is considered as a paving material.

Asphalt-cement and Olive Husk Ash (OHA) were used in the current research. Asphalt-cement grade 60-70 was produced from the petroleum refinery company at Zerqa, Jordan. The properties of asphalt-cement are listed in Table 1. $\mathrm{OHA}$ was obtained by burning olive husk at $400^{\circ} \mathrm{C}$. The chemical composition and gradation of the OHA are listed in Table 2 .

\subsection{Method of preparation of OHA-asphalt binder}

The needed equivalent volume of the OHA was computed and prepared, the percentages of the OHA were: $0 \%, 5 \%, 10 \%$, $15 \%$, and $20 \%$ depending on the volume of the mixture. The OHA was added to the heated asphalt gradually while mixing the binder to ensure consistency of the mixture and then cooled to the temperature of testing specimens.

\subsection{Measurements}

Various tests are used for determining and measuring the properties of asphalt cement (binder) with the addition of OHA For each blend of OHA-asphalt, measurements for penetration ductility, fire and flash point, softening point, and specific gravity were conducted. An average value of three specimens' measurements for each blend is listed in Table 3 .

Table 1. Properties of asphalt-cement

\begin{tabular}{ccc}
\hline Properties & ASTM Test Designation & Test Result \\
\hline Penetration $(0.1 \mathrm{~mm})$ at $25^{\circ} \mathrm{C}, 100 \mathrm{gm}$, and $5 \mathrm{sec}$ & $\mathrm{D} 5$ \\
\hline Ductility $(\mathrm{cm})$ at $25^{\circ} \mathrm{C}$ & $\mathrm{D} 113$ & 114 \\
\hline Softening Point, ${ }^{\circ} \mathrm{C}$ & $\mathrm{D} 36$ & 50 \\
\hline Flash Point, ${ }^{\circ} \mathrm{C}$ & $\mathrm{D} 92$ & \\
\hline Fire Point, ${ }^{\circ} \mathrm{C}$ & $\mathrm{D} 92$ & \\
\hline Specific Gravity & D70 \\
\hline
\end{tabular}


Table 2. Olive husk ash chemical composition and gradation [13]

\begin{tabular}{|c|c|c|c|c|c|}
\hline \multicolumn{2}{|c|}{ A-Chemical Analysis of OHA } & \multicolumn{4}{|c|}{ B-Gradation of OHA } \\
\hline Element & Percentage & Size (Micron) & Percent Finer & Size (Micron & Percent Finer \\
\hline $\mathrm{SiO}_{2}$ & 6.72 & 150 & 100.0 & 4 & 6.1 \\
\hline $\mathrm{Al}_{2} \mathrm{O}_{3}$ & 2.57 & 75 & 80.3 & 3 & 4.7 \\
\hline $\mathrm{Fe}_{2} \mathrm{O}_{3}$ & 0.67 & 48 & 69.7 & 2 & 3.1 \\
\hline $\mathrm{CaO}$ & 10.38 & 32 & 47.7 & 1.5 & 1.7 \\
\hline $\mathrm{MgO}$ & 2.14 & 24 & 35.7 & 1 & 1.3 \\
\hline $\mathrm{SO}_{3}$ & 0.61 & 16 & 23.3 & & \\
\hline $\mathrm{K}_{2} \mathrm{O}$ & 34.01 & 12 & 15.1 & & \\
\hline $\mathrm{Na}_{2} \mathrm{O}$ & 2.67 & 8 & 11.6 & & \\
\hline Loss O I & 25.55 & 6 & 8.9 & & \\
\hline
\end{tabular}

Table 3. Properties of OHA-asphalt binder \%

\begin{tabular}{|c|c|c|c|c|c|}
\hline \multirow{2}{*}{ Properties } & \multicolumn{5}{|c|}{ Olive Husk Ash by Volume of Binder (\%) } \\
\hline & $\mathbf{0}$ & 5 & 10 & 15 & 20 \\
\hline Penetration $(0.1 \mathrm{~mm})$ at $25^{\circ} \mathrm{C}, 100 \mathrm{gm}$, and $5 \mathrm{sec}$. & 65 & 52 & 45 & 34 & 25 \\
\hline Ductility, $\mathrm{cm}$ at $25^{\circ} \mathrm{C}$ & 113 & 51 & 38 & 30 & 23 \\
\hline Softening Point, ${ }^{\circ} \mathrm{C}$ & 50 & 52 & 56 & 58 & 62 \\
\hline Flash Point, ${ }^{\circ} \mathrm{C}$ & 320 & 348 & 355 & 376 & 384 \\
\hline Fire Point, ${ }^{\circ} \mathrm{C}$ & 325 & 352 & 358 & 379 & 386 \\
\hline Specific Gravity at $25^{\circ} \mathrm{C}$ & 1.017 & 1.085 & 1.162 & 1.245 & 1.288 \\
\hline
\end{tabular}

\subsubsection{Penetration test [14]}

A penetration needle creating a 100 gm equivalent force on the OHA-asphalt mixture, at $25^{\circ} \mathrm{C}$, for 5 seconds was used. The penetration distance into the OHA-asphalt mixture of the needle, in units of $0.1 \mathrm{~mm}$, was reported. The softness of mixtures with greater penetration numbers is called "soft" and is used for cold-climates in addition to asphalt mixtures with low penetration numbers called "hard" are used for warmclimates.

\subsubsection{Ductility [15]}

The ductility of a bituminous material is measured by the distance to which it will elongate before cracking when two ends of a briquette specimen of material are pulled apart at a precise speed and a precise temperature. The test shall be made at a temperature $25 \pm 0.5^{\circ} \mathrm{C}$ and with a speed of $5 \mathrm{~cm} / \mathrm{min} \pm$ $5.0 \%$. The ductility for each blend has been measured and an average value for three specimens' measurements is reported.

\subsubsection{Softening point (ring and ball) [16]}

This test covers the determination of the softening point of asphalt in the range from $30^{\circ} \mathrm{C}$ to $175^{\circ} \mathrm{C}$ using the ring and ball apparatus in an ethylene glycol bath. A steel ball of specified weight is located upon a disk of a sample contained within horizontal equipment. The component is heated in the path. Prescribed rate and the softening point taken as the temperature at which the sample becomes soft enough to allow the ball envelop in the sample material, logged the temperature when the ball attaches the plate.

The softening point is described as the temperature at which a bitumen sample is not able to stand the weight of a 3.5-g steel ball. The Ring and ball apparatus was used to obtain the softening point for each blend of the OHA-asphalt.

\subsubsection{Flash and fire point [17]}

This method covers reporting flash and fire points of all petroleum products except fuel oils. The procedure is as follows: First, the test cup is filled to a certain level with the specimen. Then, the temperature of the specimen is increased rapidly at first and then at a low constant rate as the flashpoint is reached. After that, and at specified intervals, a small test flame is passed across the cup. The lowest temperature at which the application of the test flame causes the vapors above the surface of the liquid to ignite is taken as the flashpoint. Also, to report the fire point, the test is continued until the implementation of the test flame causes the oil to ignite and burn for at least 5 seconds. This test was used to obtain the flash and fire point for each blend of OHA-asphalt mixtures. Executed on the OHA-asphalt mixture, the flashpoint of a mixture is calculated to guarantee that it is okay to work with the mixture at construction temperatures.

\subsubsection{Specific gravity [18]}

The specific gravity of asphalt cement (binder) is being used mainly for two reasons.

(1) Asphalt enlarges when heated and shrinks when cooled; this means that the volume of a given amount of asphalt cement (binder) will be increased at higher temperatures and decreased at lower ones. Thus, there must be designates measures to modify the temperature-volume.

(2) It is necessary to determine the percentage of voids in the compacted pavement. The addition of OHA to asphalt cement (binder) was in several percentages. These percentages were recorded and reported when used.

\section{RESULTS AND DISCUSSION}

Several tests were conducted according to the ASTM designation to investigate the effects of OHA content by volume of binder $(0 \%, 5 \%, 10 \%, 15 \%$, and $20 \%)$ of asphaltcement. Asphalt binder properties with ash are listed in Table 3 and shown in Figure 1 below. Equations and R-squared values are displayed in Figure 1.

\subsection{Penetration}

The effects of OHA percentage on the penetration of the OHA-asphalt-cement binder are shown in Table 3 and Figure 1(a). Report to the nearest whole unit the average of three 
penetrations whose values do not differ from the standard. It can be seen that an increase of OHA content will decrease penetration which can be explained by the fact that adding $\mathrm{OHA}$ to the asphalt-cement will increase its hardness.

\subsection{Ductility}

Report the average of three normal tests as the ductility of the sample. The effects of the percentage of OHA on the ductility of the OHA-asphalt-cement binder are shown in Table 3 and Figure 1(b). It can be seen that an increase in OHA content will decrease ductility due to an increase in asphalt binder tensile strength and stiffness.

\subsection{Softening point}

Report to the nearest $0.5^{\circ} \mathrm{C}$ the mean of the temperatures recorded in duplicate determination as the softening point. Table 3 and Figure 1(c) below indicate the effect of the percentage of OHA on the binder softening point. It can be seen than an increase in OHA content will increase the softening point.

\subsection{Fire and flash point}

To determine the fire point, the test is continued until the implementation of the test flame causes the oil to ignite and burn for at least 5 seconds. The effect of the OHA percentage on fire and flashpoint of the OHA-asphalt binder is shown in Table 3 and Figure 1(e) below. It can be seen that an increase in OHA content will increase the fire and flash point of asphalt binder since it increases asphalt binder viscosity.

\subsection{Specific gravity}

The effect of the percentage of OHA on the specific gravity of the OHA-asphalt-cement binder is shown in Table 3 and Figure 1(d) below. One could notice that an increase in OHA content will increase the specific gravity since OHA has a greater value of specific gravity compared to the value of the specific gravity of the asphalt-cement mixture. As asphalt expands when heated and contract when cooled, the volume of a given amount of asphalt cement (binder) will be greater at higher temperatures than at lower ones. Thus, there will be a need for temperature-volume correction means.

\section{b) Ductility}

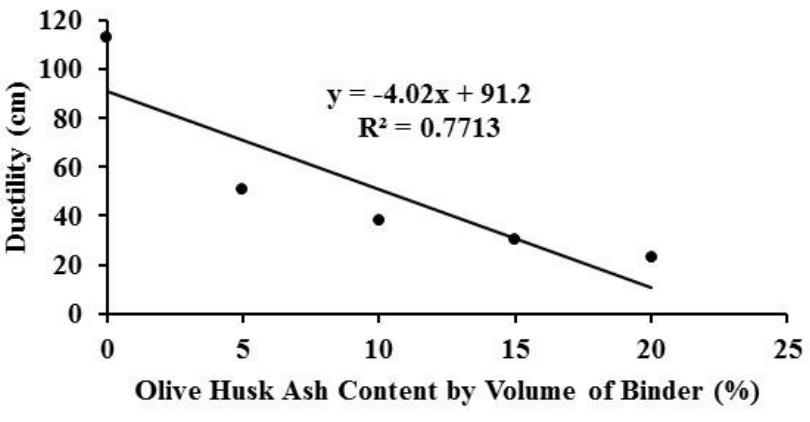

d) Specific Gravity

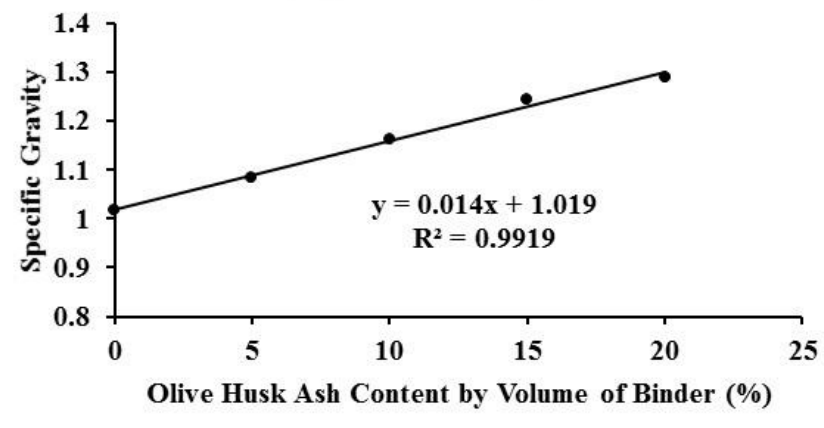

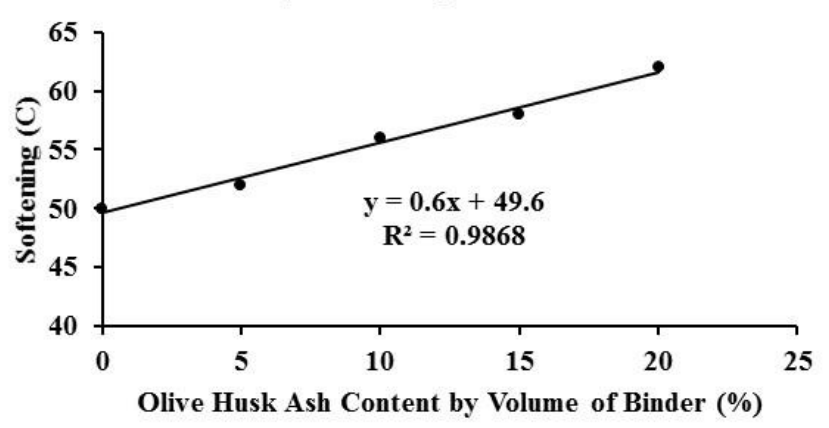

e) Flash and Fire Point

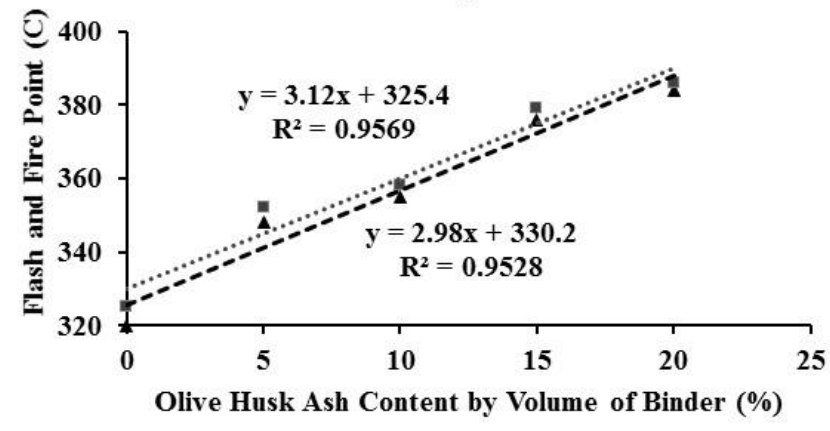

- Flash Point (C)

- Fire Point (C)

- - - Linear (Flash Point (C))

...... Lin ear (Fire Point (C))

Figure 1. Effect of olive husk ash on properties of asphalt-cement 


\section{CONCLUSIONS}

In this study, OHA is used as an additive $(0 \%, 5 \%, 10 \%$, $15 \%$, and $20 \%$ ) of asphalt-cement to investigate the effects of OHA on asphalt binder properties such as penetration ductility, softening point, fire and flashpoint, and specific gravity. The following conclusions are drawn from the current research:

(1) The increase of the Olive Husk Ash (OHA) additive content has resulted in a decrease in values of penetration and ductility of OHA-asphalt binder according to the following linear regression equations: Pentration $(0.1 \mathrm{~mm})=-1.96 \mathrm{OHA}+63.8$

Ductility $(\mathrm{cm})=-4.02$ OHA +91.2

(2) The increase of the Olive Husk Ash (OHA) additive content has resulted in an increase in the values of the softening point, fire and flashpoint, and specific gravity of OHA-asphalt binder according to the following linear regression equations:

Softening point $\left({ }^{\circ} \mathrm{C}\right)=0.6 \mathrm{OHA}+49.6$

Fire point $\left({ }^{\circ} \mathrm{C}\right)=2.98 \mathrm{OHA}+330.2$

Flash point $\left({ }^{\circ} \mathrm{C}\right)=3.12 \mathrm{OHA}+325.4$

Specific gravity $\left(\right.$ at $\left.25^{\circ} \mathrm{C}\right)=0.014 \mathrm{OHA}+1.019$

\section{ACKNOWLEDGMENT}

The authors would like to express their sincere gratitude to the Civil Engineering Departments of Jordan University of Science and Technology, Ajloun National University, and the UAE University for their help in conducting this research.

\section{REFERENCES}

[1] Al-Massaid, H., Khedaywi, T., Smadi, M. (1989). Properties of asphalt-oil shale ash bituminous mixtures under normal and freeze-thaw conditions. Transportation Research Record, 1228: 54-62.

http://onlinepubs.trb.org/Onlinepubs/trr/1989/1228/122 8-007.pdf.

[2] Al-Massaid, H., Hamed, M., Khedaywi, T. (1994). Empirical evaluation of olive husk in asphalt cement binder and bituminous concrete. Transportation Research Record, 1436: 124-132. http://onlinepubs.trb.org/Onlinepubs/trr/1994/1436/143 6-015.pdf.

[3] Al-Mashgbeh, J.M. (2002). Evaluation of the effect of rubber on fatigue characterization and permanent deformation of asphalt concrete mixtures. Master Thesis. Civil Engineering Department, Jordan University of Science and Technology, Irbid, Jordan.

[4] Dartnell, L. (1967). Study of limestone dust, calcined shale and asbestos mineral filler in asphalt paving mixtures. Canadian Technical Asphalt Association Proceeding, 12: 51-60.

[5] Al Qadi, A.N. (2002). Effect of oil shale ash on fatigue behavior and rutting of flexible pavement. Master Thesis. Civil Engineering Department, Jordan University of Science and Technology, Irbid, Jordan.

[6] Khedaywi, T., Abu-Orabi, S. (1989). Effect of oil shale ash, rubber ash, husk ash and polyethylene of asphalt cement. Journal of Petroleum Research, 8(2): 193-206.

[7] Hui, P., Morrison, G., Hesp, S. (1994). Improved lowtemperature fracture performance for rubber-modified asphalt binder. Transportation Research Record, 1436: 83-87.

[8] Fayer, G.A. (1994). Use of rubber-modified in asphalt pavement. Kansas Experience, TRB, 1436, National Research Council, Washington, D.C., 1436: 88-97.

[9] Hanson, D.I., Foo, K.Y., Brown, E.R., Denston, R. (1994). Evaluation and characterization of a rubbermodified hot mix asphalt pavement. Transportation Research $\quad$ Record, 1436: 98-107. http://worldcat.org/isbn/030905513X

[10] Alsheyab, M.A.T., Khedaywi. T.S. (2013). Effect of electric arc furnace dust (EAFD) on properties of asphalt cement mixture. Resources, Conservation and Recycling Journal, 70: 38-43. https://doi.org/10.1016/j.resconrec.2012.10.003

[11] Gautam, P.K., Kalla, P., Jethoo, A.S., Agrawa, R. Singh, H. (2018). Sustainable use of waste in flexible pavement: A review. Construction and Building Materials, 180: 239-253. https://doi.org/10.1016/j.conbuildmat.2018.04.067

[12] Arafat, S., Kumar, N., Wasiuddin, N.M., Owh, E.O., Lynam, J.G. (2019). Sustainable lignin to enhance asphalt binder oxidative aging properties and mix properties. Journal of Cleaner Production, 217: 56-68. https://doi.org/10.1016/j.jclepro.2019.01.238

[13] ASTM D6913-04. (2004). Standard Test Methods for Particle-Size Distribution (Gradation) of Soils Using Sieve Analysis. ASTM International. West Conshohocken, PA, USA. www.astm.org.

[14] ASTM D5 / D5M - 20 Standard Test Method for Penetration of Bituminous Materials. Developed by Subcommittee: D04.44

[15] ASTM D113-17. (2017). Standard Test Method for Ductility of Asphalt Materials. ASTM International. West Conshohocken, PA, USA. www.astm.org.

[16] ASTM D36 / D36M-14. (2020). Standard Test Method for Softening Point of Bitumen (Ring-and-Ball Apparatus). ASTM International. West Conshohocken, PA, USA. www.astm.org.

[17] ASTM D92-18. (2018). Standard Test Method for Flash and Fire Points by Cleveland Open Cup Tester. ASTM International. West Conshohocken, PA, USA. www.astm.org.

[18] ASTM D70-18a. (2018). Standard Test Method for Density of Semi-Solid Asphalt Binder (Pycnometer Method). ASTM International. West Conshohocken, PA, USA. www.astm.org. 